\title{
Inpatient care of patients with type I diabetes mellitus by duration of diabetes and sex: A nationwide population-based longitudinal study
}

This article was published in the following Dove Press journal:

Risk Management and Healthcare Policy

17 July 2009

Number of times this article has been viewed

\author{
Markku J Akkanen ${ }^{1,4}$ \\ Sirkka-Liisa Kivelä ${ }^{2}$ \\ Veli Koistinen ${ }^{3}$ \\ Harri Sintonen ${ }^{4}$ \\ Jaakko Tuomilehto ${ }^{4}$ \\ 'Welfare and Health Promotion \\ Division, Department of Chronic \\ Disease Prevention, Diabetes \\ Prevention Unit, National Institute \\ for Health and Welfare (THL), \\ Helsinki, Finland; ${ }^{2}$ Turku University \\ of Central Hospital, Turku, Finland; \\ ${ }^{3}$ Department of Health Policy and \\ Management, University of Kuopio, \\ Kuopio, Finland; ${ }^{4}$ Department of \\ Public Health, University of Helsinki, \\ Helsinki, Finland
}

Aims: To describe hospitalizations of a cohort of patients with type 1 diabetes mellitus (T1DM) during 1973-1998 in the main complication groups by sex and T1DM lasting on average 9.5 or 16.5 years.

Material and methods: The population $(\mathrm{N}=5166)$ consisted of all Finnish patients with T1DM diagnosed before the age of 18 years between 1965-1979, derived from the Finnish population-based register of T1DM patients. Data on hospitalizations were obtained from the Finnish Hospital Discharge Register.

Results: In the early stages of T1DM, the majority of the use of hospitalizations was due to the treatment of T1DM without complications. Enormous increases were found for complications when diabetes lasted longer (from 9.5 to 16.5 years). For women, the yearly number of bed-days for renal complications increased 4.8-fold, for peripheral vascular disease 4.3-fold, and for ophthalmic complications 2.5-fold. For men, the corresponding increases were as follows: 5-fold, 6.9-fold, and 2.5-fold. The yearly number of bed-days for nephropathy increased 7-fold. Bed-days for T1DM without complications dropped dramatically. The length of stay in hospitalizations decreased notably, but hospital visits increased when the duration of T1DM increased.

Conclusions: Hospitalizations due to complications substantially increase with aging of T1DM patients. Prevention of T1DM is strongly needed.

Keywords: T1DM, inpatient care, hospitalizations, complications

\section{Introduction}

Diabetes has major long-term implications, not only for the health and well-being of individuals, but also for health services costs. ${ }^{1}$ Diabetes may cause many complications, such as retinopathy, nephropathy, cardiac and cerebrovascular disease, and peripheral vascular disease with neuropathy, and the probability of developing these is related to the duration of diabetes and the metabolic control. ${ }^{2}$ Diabetic ketoacidosis and severe hypoglycemia are acute complications that may be life-threatening. ${ }^{3}$ Patients with diabetes are also at increased risk for secondary complications, eg, influenza-associated respiratory illnesses. ${ }^{4}$ Inpatient hospital care is the major contributor to the health care costs of diabetes. ${ }^{5-9}$ In addition to glycosylated hemoglobin as a significant predictor of diabetes complications, urine albumin:creatine ratio, body mass index, triglycerides, and high-density lipoproteins are independent predictors of hospitalizations for complications due to diabetes. ${ }^{10}$ Even a modest reduction in hospitalizations of people with diabetes could result in major savings; ${ }^{11}$ hospitalization data are crucial in developing strategies for preventing hospitalizations. ${ }^{12}$

\footnotetext{
Correspondence: Markku J Akkanen Department of Public Health, University of Helsinki, Helsinki, Finland; and National Institute for Health and Welfare (THL), Welfare and Health Promotion Division, Department of Chronic Disease Prevention, Diabetes Prevention Unit, PO Box 30, Fl-0027I Helsinki, Finland Tel +358919127614

Fax +358919127313

Email juho.akkanen@welho.com
} 
As the burden of diabetes is increasing, it is vital to develop new prevention strategies and treatments. There have been several multicenter clinical trials designed to prevent type 1 diabetes mellitus (T1DM), which have tested nicotinamide, parenteral insulin, oral insulin, nasal insulin, and the elimination of cow's milk from infant feeding. ${ }^{13}$ These studies were aimed at preventing or delaying clinical T1DM, and have given certain hope that T1DM can be prevented, as new studies are emerging. ${ }^{13,14}$ Developing a vaccine for enterovirus is a new field of study, which looks promising in prevention of T1DM. ${ }^{14}$

In the studies conducted mainly in the United States, insulin analogs were noticed to offer a better balance between glycemic control and hypoglycemia when compared with human insulins, and the subsequent potential to reduce the costs of hospital treatments and chronic complications. ${ }^{15}$

In Finland, the incidence of T1DM is the highest in the world. ${ }^{16,17}$ Since the beginning of the 1990 s, the incidence has increased, reaching 60 per 100,000 person-years in $2005 .{ }^{18}$ The medical and financial burden of diabetes will increase on the Finnish society, on the health care sector and on affected persons, as the number of patients with severe complications may rise. The need for health economic information, especially longitudinal, about T1DM will become more stressed.

In Finland, nationwide data on incident cases of childhood-onset diabetes exist since $1965 .{ }^{19}$ These data form a good basis for research into the epidemiology and health services utilization in patients with T1DM. The overall aim of this study was to describe the use of inpatient care of a cohort of childhood-onset diabetic patients prospectively during 1973 to 1998 , especially in the main categories of diabetic complications.

\section{Material and methods}

The population consisted of all Finnish T1DM patients diagnosed before the age of 18 years between January 1st, 1965 and December 31st, 1979 and derived from the Finnish population-based register with patients with T1DM. At the end of 1979, this dynamic cohort consisted of 5,166 patients (2,327 females, 2,839 males).

The Finnish population-based register belongs to the material of the Diabetes Epidemiology Research International (DERI) Study, which has been used in evaluating mortality in T1DM..$^{20-22}$ The register was established by linking the Finnish Hospital Discharge Register (FHDR) with the Social Insurance Institution Central Drug Register using the unique personal identification numbers recorded in both registers. The Central Drug Registry only recorded the date of approval of the free-of-charge medication, so copies of the original certificates had been collected for the years 1965-1979 to obtain the actual dates of diagnosis. ${ }^{19}$ Data on hospitalizations were obtained from the FHDR.

Two cohorts were formed based on the duration of diabetes. The hospitalizations during two three-year periods of duration, 9-11 and 16-18 years, were compared in nine complication groups associated with diabetes. ${ }^{23}$ The nine complication groups were the following: cerebrovascular disease, cardiac disease, peripheral vascular disease, neurological complications, renal complications, endocrine complications, ophthalmic complications, other complications, and coma. The complications and complication groups were based on the criteria of the American Diabetes Association. ${ }^{24}$ Cerebrovascular complications were extracted from neurological disorders. Diabetic coma was included as a separate group. The main diagnosis of each hospitalization was used in calculations. Hospitalizations in nine complication groups were compared between these two three-year periods (9-11 and 16-18 years). Hospitalizations were first calculated for these three-year periods and then divided by three, indicating the effect of duration on hospitalizations when diabetes had lasted on average 9.5 years compared with 16.5 years. The amount of hospitalizations due to each complication group was compared with the amount of use due to all complications, hospitalizations due to other causes than diabetes, and hospitalizations due to all hospitalizations (due to any cause). Diabetes-related hospitalizations due to diabetic complications, and without complications (International Code of Diseases [ICD]: ICD- 8 code 25000 and ICD-9 code 2500B) were also calculated separately. The results were presented by ICD-9 codes, and ICD- 8 codes were converted to correspond to ICD-9 codes, because the coding changed in 1987. ICD-10 was officially adopted on January 1st, 1996 in Finland (the first edition was published in 1995 and the second one in 1998). The ICD-10 codes for diabetes in FHDR changed markedly compared to the earlier versions (ICD-8 and ICD-9) and if this study could have used ICD-10 codes, another translation of the codes would have been needed, which would have complicated and biased the study too much.

The exact dates of death were used when calculating the number of patients alive (N1) in the beginning and at the end (N2) of the two periods, and then summed and divided by $2(\mathrm{~N} 1+\mathrm{N} 2 / 2)$ in order to obtain the average number of people 
alive during the two study periods. The average number of patients was 5,120 in the 9.5-year cohort and 5,010 in the 16.5-year cohort. These figures were used in calculating bed-days and discharges per 1,000 patients.

The following principles were applied in calculations:

- If there were two days or less between two treatment periods, they were defined as two different treatment periods if the main diagnoses of the periods were different. If the main diagnoses of the periods were the same, the periods were defined as one treatment period.

- The days of admission to hospital and discharge from hospital were treated as a single bed-day.

- Overlapping treatment periods of the same patient in two different locations were either errors or due to specific consultations and thus the overlapping part was omitted in order to avoid overestimation of bed-days.

- Discharge (treatment period): Hospitalization period lasting for at least 15 hours.

- Average length of stay (LOS): The number of hospital days divided by the number of treatment periods (discharges).

- Bed-days per user: The number of bed-days divided by the number of patients who used hospital at least once during the period concerned.

- As pregnancy is not a disease, hospitalizations due to pregnancies were omitted, eg, for comparison purposes (men/women).

\section{Results}

The mean age at diagnosis in the cohort was 10.3 years (standard deviation [SD] 4.4; min 0.7 and max 17.9). When the average duration of diabetes was 9.5 or 16.5 years, the mean ages of patients were 20 years ( $\min 10 ; \max 27.5$ ) and 27 years ( $\min 17$; $\max 34.5$ ), respectively. Hospitalizations occurred between 1973-1998, follow-up being 26 years. The number of hospital users are shown in Table 1.

\section{Bed-days for total population}

In the 9.5-year cohort, the shares of bed-days of other complications, ophthalmic complications, renal complications and coma were the biggest, and their shares of the total amount of bed-days were $6.0 \%, 3.6 \%, 2.2 \%$, and $1.5 \%$, respectively.

In the 16.5-year cohort other, renal, ophthalmic and peripheral vascular complications constituted the biggest shares of the amount of bed-days of all complications. Especially renal, but also peripheral vascular and cardiovascular complications showed the biggest increases in shares compared with the 9.5-year cohort, while the shares of other complications and coma dropped clearly. The shares of other, renal, ophthalmic and peripheral vascular complications of the total amount of bed-days were $15.0 \%, 12.1 \%, 11.3 \%$, and $3.0 \%$, respectively. The share of the first four complication groups combined (cerebrovascular, cardiovascular, peripheral vascular, and neurological complications) increased from $1.3 \%$ to $5.5 \%$.

Table I Number of hospital users during the periods of three years by sex and duration of diabetes (by complication groups, complications combined, TIDM without complications and total number)

\begin{tabular}{|c|c|c|c|c|c|c|}
\hline & No. of females & No. of males & No. of females & No. of males & & \\
\hline & TIDM & TIDM & TIDM & TIDM & TIDM & TIDM \\
\hline & 9-II yrs. & 9-II yrs. & $16-18$ yrs. & $16-18$ yrs. & 9-II yrs. & $16-18$ yrs. \\
\hline CERVASC & 3 & 2 & 7 & 3 & 5 & 10 \\
\hline CARVASC & 2 & 7 & 8 & 15 & 9 & 23 \\
\hline PERVASC & 11 & 12 & 60 & 53 & 23 & 113 \\
\hline NEUROL & 11 & 18 & 32 & 25 & 29 & 57 \\
\hline RENAL & 47 & 33 & 173 & 107 & 80 & 280 \\
\hline ENDOCRIN & 0 & 0 & 0 & 1 & 0 & 1 \\
\hline OPHTHALMIC & 104 & 77 & 271 & 230 & $|8|$ & 501 \\
\hline OTHER complicat. & 112 & 122 & 166 & 164 & 234 & 330 \\
\hline COMA & 45 & 38 & 18 & 32 & 83 & 50 \\
\hline $\begin{array}{l}\text { Complications } \\
\text { total }\end{array}$ & 295 & 274 & 555 & 495 & 569 & 1050 \\
\hline $2500 \mathrm{~B} / 25000$ & 1106 & 1042 & 469 & 457 & 2148 & 926 \\
\hline TOTAL use & 1349 & 1378 & 1213 & || $7 \mid$ & 2727 & 2384 \\
\hline
\end{tabular}

Abbreviations: Cervasc, cerebrovascular disease; carvasc, cardiac disease; pervasc, peripheral vascular disease; neurol, neurological complications; renal, renal complications; endocrine, endocrine complications; ophthalmic, ophthalmic complications; 2500B/25000,TIDM without complications (ICD-9/ICD-8 codes). 
The total yearly number of bed-days used due to complications during the first and second three-year periods increased from 6,742 to 18,158 days, while the number of bed-days used due to any cause decreased from 45,986 to 40,669 days. The share of the bed-days of the nine complication groups of the total amount of bed-days rose from $14.7 \%$ to $44.6 \%$. The number of bed-days due to diabetes without complications dropped by $73 \%$.

As calculated by the mean numbers of yearly bed-days per 1,000 patients by the complication group and the duration of diabetes, other complications remained the biggest complication group when the duration of diabetes increased, while renal diseases replaced ophthalmic diseases as the second biggest group. Hospitalizations due to cardiovascular $(+1,406 \%)$, peripheral vascular $(+474 \%)$, renal $(+387 \%)$, ophthalmic $(+185 \%)$, cerebrovascular $(+131 \%)$, other $(+126 \%)$ and neurological (+52\%) complications increased. Endocrine complications were practically nonexistent. Beddays due to coma decreased by $54 \%$.

\section{Bed-days by sex}

Female patients had a bigger share of bed-days due to ophthalmic complications than men while male patients had a bigger share due to other complications in the 9.5-year cohort (Figure 1). In the 16.5-year cohort female patients had a bigger share of bed-days due to renal complications while male patients had a bigger share due to peripheral complications. The biggest change in the shares of bed-days of any complication group was the increases in shares of renal complications in both sexes.

Female patients used more bed-days per 1,000 patientyears than males; in the 9.5-year cohort for all hospitalizations $39 \%$ more and in the 16.5 -year cohort $32 \%$ more than males, and for hospitalizations due to complications $32 \%$ and $30 \%$ more, respectively. Female patients had used almost twice more bed-days (per 1,000 patient-years) due to ophthalmic complications than males in the 9.5 -year cohort and $47 \%$ more in the 16.5 -year cohort, and $60 \%$ more yearly bed-days due to renal complications in the 9.5 -year cohort and $55 \%$ more in the 16.5 -year cohort. Male patients had used $52 \%$ more yearly bed-days due to peripheral vascular complications when diabetes lasted longer. The number of bed-days due to coma dropped more in female than male patients.

There were marked increases in the yearly number of bed-days due to certain complications when diabetes had lasted longer. From the 9.5-year cohort to the 16.5-year cohort, the number of bed-days due to renal complications

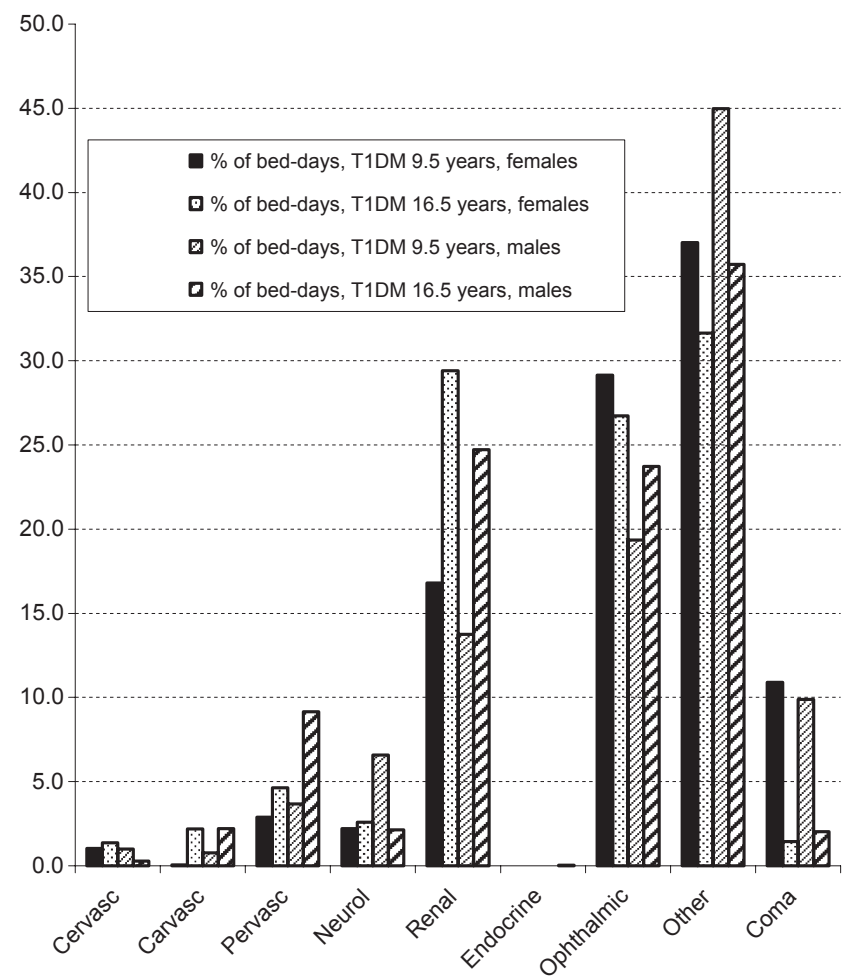

Figure I Percentages of yearly bed-days due to complications out of all bed-days due to complications by complication group, duration of type I diabetes (TIDM) and sex. Abbreviations: Cervasc, cerebrovascular disease; Carvasc, cardiac disease; Pervasc, Peripheral vascular disease; neurol, neurological complications; renal, renal complications; endocrin, endocrin complications; ophthalmic, ophthalmic complications; other, other complications.

increased 4.8-fold, peripheral vascular complications 4.3-fold, neurological complications 3.2-fold, ophthalmic complications 2.5 -fold, and other complications 2.3 -fold in female patients. In male patients, the number of bed-days due to peripheral vascular complications increased 6.9-fold, renal complications 5-fold, ophthalmic complications 3.4-fold, and other complications 2.2-fold.

\section{Length of stay}

In all complication groups combined there was a drop in average length of stay (LOS) from 7.7 (SD 8.1) to 6.9 days (SD 9.2), and LOS for total inpatient care (for any cause) dropped from 7.4 (SD 10.3) to 6.4 days (SD 19.2), as the duration of diabetes increased by seven years. Generally, male patients seemed to have stayed slightly longer in hospital during their treatment periods than females. Among both sexes, LOS for many complications seemed to decrease, and LOS due to ophthalmic complications and coma had a clear drop among both sexes (1.7 to 1.9 days), as did LOS due to renal complications among female patients (8.9 to 7.1 days). LOS due to cardiovascular complications increased in both sexes, and LOS due to cerebrovascular complications 
increased in women, but decreased in men. The number of patients in these two groups however was small.

\section{Most common diagnoses}

Regarding total inpatient care, diabetes without complications was a dominating diagnosis when diabetes had lasted 9-11 years, representing $61 \%$ of all bed-days and $71 \%$ of bed-days due to other causes than complications (Table 2). The number of bed-days due to the treatment of diabetes without complications was 4.2-fold that due to the treatment of complications when diabetes had lasted 9-11 years. Its share dropped by $73 \%$, when the duration of diabetes increased by seven years. The number of bed-days for treating diabetic nephropathy showed a seven-fold rise when the duration of diabetes increased.

The number of bed-days for treating all other defined complications, ophthalmic complications and retinopathy increased over 3-fold, while the number of bed-days for treating nondefined complications decreased 63\% when diabetes lasted longer.

Treatment of mental diseases and disorders (eg, various personality disorders, schizophrenia, and depression) seemed to cause a large number of bed-days and long treatment periods. Measured by the number of bed-days and discharges, ketoacidosis, diabetic microangiopathy, diabetic neuropathy, and coma were among the most common diagnoses in the cohort with a longer duration of diabetes. The changes in the number of bed-days during the two three-year periods relating to certain diagnoses of ophthalmic complications turned out to be interesting. The number of bed-days due to treatment of glaucoma was 8 -fold and that due to treatment of diabetic retinopathy 2.7 -fold in the 16.5 -year cohort compared with the 9.5-year cohort.

\section{Discussion}

Drug treatment for diabetes is free of charge in Finland. Patients receive reimbursement from the Social Insurance Institution after the institution has approved the application based on a certificate from the physician. Only occasionally the parents of a diabetic child fail to seek reimbursement for insulin costs, and the child is not included in the nationwide Central Drug Registry. The ascertainment rate of childhood diabetes is almost $100 \% ;^{19}$ the case ascertainment in this cohort was virtually complete. ${ }^{19,25}$

In Finland, there are better possibilities to conduct register-based health studies than in most other countries, as the coverage of registers is good and their quality for research purposes is excellent. It is possible to link registers with a personal identification code. ${ }^{26}$ The accuracy and quality of the FHDR data for epidemiological research purposes have been estimated. ${ }^{26-31}$ In a comparison of coded diagnoses with hospital records during the corresponding hospital stay, 95\% of the main diagnoses and $96 \%$ of the dates of admission and discharge were correct in 1986.

The main diagnoses of hospital discharges were compared. Thus, the inferior accuracy of the secondary diagnoses in FHDR had no relevance. The use of primary diagnosis also prevented double counting, that can happen when multiple diagnoses are used.

Hospitalizations after diabetes durations of 9-11 and 16-18 years were compared. The hospitalizations were first considered in three-year periods to obtain steadier frequencies across years and to damp fluctuations. These three-year numbers were divided by three to get yearly figures and to demonstrate how hospital use differs in complication groups when diabetes has lasted on average 9.5 years compared with 16.5 years. Yearly inpatient care was calculated per 1,000 patients to adjust for different numbers of men and women and to take into account mortality.

Ketoacidosis and hypoglycemia have ICD-9 codes, but not ICD-8 codes. Their inclusion in complication grouping would have distorted the comparisons so they were excluded from the main groupings. Physicians in hospital may have coded these into secondary diagnoses, or most likely into group other complications (diabetes with other specified/ unspecified complications; Table 2). This is supported by the fact, that besides the number of bed-days, number of hospital users also clearly increased in that group (Table 1).

The lack of ICD- 8 codes for microangiopathy may have caused an underestimation of peripheral vascular complications in the younger group, and an overestimation of the growth as diabetes lasted longer.

No hospital periods exceeding 365 days existed in hospital use for any complication group during the two three-year observation periods; very long hospital periods ("outliers") did not affect the results. Only a few shorter outliers were observed, which raised the means of bed-days in certain groups and observation periods.

Hospital use due to complications increased markedly; the numbers of hospital users doubled, the annual number of discharges increased 3-fold and that of bed-days 2.8-fold when diabetes lasted longer.

With increasing duration of diabetes, the length of stay decreased in all complication groups, except in cerebrovascular, cardiovascular, and peripheral vascular complications. Although the LOS in hospital generally 
Table 2 Number of bed-days and discharges, and mean length of stay (LOS) of diseases (by diagnoses) causing most inpatient care in complication groups (ranked by the amount of bed-days) and for total use in the two observation period of three years of TIDM duration

\begin{tabular}{|c|c|c|c|c|c|c|c|}
\hline \multicolumn{4}{|c|}{ TIDM duration 9-II years } & \multicolumn{4}{|c|}{ TIDM duration $16-18$ years } \\
\hline Bed-days & Discharges & LOS & Diagnosis & Bed-days & Discharges & LOS & Diagnosis \\
\hline \multicolumn{8}{|c|}{ Total hospital use } \\
\hline 28045 & 3856 & 7.3 & $\begin{array}{l}\text { Diabetes without } \\
\text { complications }\end{array}$ & 7711 & 1539 & 5.0 & $\begin{array}{l}\text { Diabetes without } \\
\text { complications }\end{array}$ \\
\hline 1801 & 229 & 7.9 & $\begin{array}{l}\text { Diabetes with other specified } \\
\text { complications }\end{array}$ & 5707 & 644 & 8.9 & $\begin{array}{l}\text { Diabetes with other specified } \\
\text { complications }\end{array}$ \\
\hline 1345 & 185 & 7.3 & $\begin{array}{l}\text { Diabetes with ophthalmic } \\
\text { complications + retinopathy }\end{array}$ & 4262 & 537 & 7.9 & Diabetic nephropathy \\
\hline 1048 & 20 & 52.4 & $\begin{array}{l}\text { Anxiety dissociative and } \\
\text { somatoform disorders }\end{array}$ & 4012 & 756 & 5.3 & $\begin{array}{l}\text { Diabetes with ophthalmic } \\
\text { complications + retinopathy }\end{array}$ \\
\hline 749 & 76 & 9.9 & $\begin{array}{l}\text { Diabetes with unspecified } \\
\text { complication }\end{array}$ & 1978 & 6 & 329.7 & Schizophrenic disorders \\
\hline 696 & 106 & 6.6 & Diabetes with hyperosmolarity & 1310 & 43 & 30.5 & Personality disorders \\
\hline 643 & 9 & 71.4 & Schizophrenic disorders & 609 & $|4|$ & 4.3 & Diabetes with ketoacidosis \\
\hline 609 & 74 & 8.2 & Diabetic nephropathy & 551 & 111 & 5.0 & Microangiopathy \\
\hline 602 & 15 & 40.1 & Personality disorders & 431 & 25 & 17.2 & Multiple sclerosis \\
\hline 347 & 72 & 4.8 & Diabetes with ketoacidosis & 385 & 59 & 6.5 & Diabetic neuropathy \\
\hline \multirow[t]{2}{*}{345} & 4 & 86.3 & Episodic mood disorders & 317 & 13 & 24.4 & $\begin{array}{l}\text { Rheumatoid arthritis } \\
\text { specified }\end{array}$ \\
\hline & & & & 312 & 65 & 4.8 & $\begin{array}{l}\text { Diabetes with } \\
\text { hyperosmolarity }\end{array}$ \\
\hline \multicolumn{8}{|c|}{ Cerebrovascular complications } \\
\hline 30 & I & 30.0 & Cerebral embolism & 96 & 5 & 19.2 & Cerebral thrombosis \\
\hline 19 & 2 & 9.5 & Transient cerebral ischemia & 38 & 1 & 38.0 & $\begin{array}{l}\text { Other cerebrovascular } \\
\text { disorders }\end{array}$ \\
\hline 16 & I & 16.0 & Intracerebral hemorrhage & 13 & 3 & 4.3 & Transient ischemic attack \\
\hline \multicolumn{8}{|c|}{ Cardiovascular complications } \\
\hline 8 & 3 & 2.7 & Atrial fibrillation & 133 & 13 & 10.2 & Acute myocardial infarction \\
\hline 7 & 2 & 3.5 & Old myocardial infarction & 75 & 2 & 37.5 & Congestive heart failure \\
\hline \multirow[t]{3}{*}{4} & 3 & 1.3 & $\begin{array}{l}\text { Other specified cardiac } \\
\text { dysrhythmias }\end{array}$ & 72 & 8 & 9.0 & Old myocardial infarction \\
\hline & & & & 24 & 2 & 12.0 & $\begin{array}{l}\text { Congestive heart failure/ } \\
\text { pulmonary edema }\end{array}$ \\
\hline & & & & 31 & 2 & 15.5 & Unstable angina pectoris \\
\hline \multicolumn{8}{|c|}{ Peripheral vascular complications } \\
\hline 90 & 11 & 8.2 & Microangiopathy & 547 & 109 & 5.0 & Microangiopathy \\
\hline 58 & 7 & 8.3 & $\begin{array}{l}\text { Chronic ulcer of other } \\
\text { specified/unspecified sites }\end{array}$ & 142 & 9 & 15.8 & $\begin{array}{l}\text { Chronic ulcer in other } \\
\text { specified/unspecified sites }\end{array}$ \\
\hline 23 & 3 & 7.7 & $\begin{array}{l}\text { Traumatic amputation of } \\
\text { thumb complicated }\end{array}$ & 117 & 7 & 16.7 & Chronic ulcer \\
\hline 16 & I & 16.0 & $\begin{array}{l}\text { Peripheral vascular disease } \\
\text { unspecified }\end{array}$ & 73 & 10 & 7.3 & Diabetic gangrene \\
\hline 16 & 2 & 8.0 & Phlebitis and thrombophlebitis & 70 & 5 & 14.0 & Ulcer in lower leg \\
\hline \multicolumn{8}{|c|}{ Neurological complications } \\
\hline \multirow[t]{3}{*}{273} & 36 & 7.6 & Diabetic neuropathy & 385 & 59 & 6.5 & Diabetic neuropathy \\
\hline & & & & 28 & 20 & 1.4 & Carpal tunnel syndrome \\
\hline & & & & 10 & 4 & 2.5 & $\begin{array}{l}\text { Peripheral nerve disorder } \\
\text { Median nerve }\end{array}$ \\
\hline
\end{tabular}


Table 2 (Continued)

\begin{tabular}{|c|c|c|c|c|c|c|c|}
\hline \multicolumn{4}{|c|}{ TIDM duration 9-I I years } & \multicolumn{4}{|c|}{ TIDM duration $16-18$ years } \\
\hline Bed-days & Discharges & LOS & Diagnosis & Bed-days & Discharges & LOS & Diagnosis \\
\hline \multicolumn{8}{|c|}{ Renal complications } \\
\hline 609 & 74 & 8.2 & Diabetic nephropathy & 4262 & 537 & 7.9 & Diabetic nephropathy \\
\hline 199 & 19 & 10.5 & $\begin{array}{l}\text { Renal infection/Acute } \\
\text { Pyelonephritis }\end{array}$ & 301 & 54 & 5.6 & $\begin{array}{l}\text { Renal infection. Acute } \\
\text { pyelonephritis }\end{array}$ \\
\hline 124 & 9 & 13.8 & $\begin{array}{l}\text { Renal infection/Chronic } \\
\text { pyelonephritis }\end{array}$ & 164 & 14 & 11.7 & $\begin{array}{l}\text { Other disease of urinary } \\
\text { tract }\end{array}$ \\
\hline 27 & 4 & 6.8 & Renal infection unspecified & 64 & 6 & 10.7 & $\begin{array}{l}\text { Renal infection. Chronic } \\
\text { pyelonephritis }\end{array}$ \\
\hline 26 & 2 & 13.0 & Acute nephritis & 43 & 8 & 5.4 & $\begin{array}{l}\text { Chronic nephritis with } \\
\text { uremia }\end{array}$ \\
\hline \multicolumn{8}{|c|}{ Endocrine complications } \\
\hline- & - & - & - & 3 & 1 & 3.0 & Hyperkalemia \\
\hline \multicolumn{8}{|c|}{ Ophthalmic complications } \\
\hline 1174 & 153 & 7.7 & Diabetic retinopathy & 3143 & 566 & 5.6 & Diabetic retinopathy \\
\hline 171 & 32 & 5.3 & $\begin{array}{l}\text { Diabetes with ophthalmic } \\
\text { complications }\end{array}$ & 739 & 174 & 4.2 & $\begin{array}{l}\text { Diabetes with ophthalmic } \\
\text { complications }\end{array}$ \\
\hline 93 & 12 & 7.8 & Diabetic cataract & 250 & 50 & 5.0 & Glaucoma \\
\hline $4 I$ & 9 & 4.6 & Acute iridocyclitis & 137 & 27 & 5.1 & Diabetic cataract \\
\hline 66 & 9 & 7.3 & Cataract & 95 & 6 & 15.8 & $\begin{array}{l}\text { Diabetes with other specified } \\
\text { ophthalmic complications }\end{array}$ \\
\hline 31 & 8 & 3.9 & Glaucoma & 80 & 22 & 3.6 & Cataract \\
\hline 27 & 3 & 9.0 & Iridocyclitis chronic uveitis & 72 & 10 & 7.2 & $\begin{array}{l}\text { Hemorrhage of vitreous } \\
\text { body }\end{array}$ \\
\hline \multicolumn{8}{|c|}{ Other complications } \\
\hline 1640 & 230 & 7.1 & $\begin{array}{l}\text { Diabetes with other specified } \\
\text { complications }\end{array}$ & 5689 & 642 & 8.9 & $\begin{array}{l}\text { Diabetes with other specified } \\
\text { complications }\end{array}$ \\
\hline 872 & 78 & 11.2 & $\begin{array}{l}\text { Diabetes with unspecified } \\
\text { complications }\end{array}$ & 277 & 57 & 4.9 & $\begin{array}{l}\text { Diabetes with unspecified } \\
\text { complications }\end{array}$ \\
\hline 115 & 13 & 8.8 & $\begin{array}{l}\text { Cellulitis. Cutaneous/ } \\
\text { subcutaneous infections }\end{array}$ & 66 & 6 & 11.0 & Chronic osteomyelitis \\
\hline 77 & 3 & 25.7 & Chronic osteomyelitis & 17 & 4 & 4.3 & $\begin{array}{l}\text { Cellulitis. Cutaneous/ } \\
\text { subcutaneous infections }\end{array}$ \\
\hline
\end{tabular}

decreased, the number of discharges per user increased, especially for other, renal, and ophthalmic complications; patients were more frequently in hospital. The number of beddays per user for complication groups increased because the drop of the LOS was offset by the increase in the frequency of hospital visits. More patients without complications may have been treated in outpatient care and at home as a result of a change in treatment practices and a rise in patients' age.

Generally, women used clearly more inpatient treatment than men. One explanation may be that women seek health care more readily than men, which has been reported earlier. ${ }^{32,33}$ Men's attitudes towards diseases and symptoms are different compared with those of women's, which may lead to men's slower reaction to seek health care. ${ }^{34}$
As diabetes lasted longer, men had a slightly bigger increase than women in the hospital use due to all complications and in the total hospital use, as measured by the number of discharges, and in the hospital use due to all complications, as measured by the number of bed-days. Women's total number of bed-days dropped slightly more than that of men. Women visited hospitals slightly more frequently than men, when total hospital use and hospital use due to other causes than diabetes were observed. Men generally stayed during their treatment periods a bit longer in hospital than women, especially considering the group of complications combined, other hospitalizations than those due to diabetes and total hospitalizations, when diabetes had lasted 9.5 years or 16.5 years; the LOS decreased for 
both sexes by about the same amount. The yearly numbers of bed-days and discharges per user considering all complications combined increased for both sexes clearly as the duration increased.

An increase in the proportion of yearly discharges due to renal complications was notably bigger for women than for men as the duration of diabetes increased, but for ophthalmic complications, men had a clearly bigger increase. The sex difference in yearly discharges was about the same in the 9.5-year cohort for ophthalmic complications as in the 16.5-year cohort for renal complications. Thus, women used hospital relatively more frequently due to ophthalmic causes than men when diabetes had lasted on average 9.5 years, but they visited hospital relatively more often for renal causes than men when the duration increased. The biggest differences between the sexes in the absolute number of discharges per 1,000 patients per year were that women had twice as much ophthalmic and over 50\% more renal complication discharges when diabetes had lasted 9.5 years, and almost $40 \%$ more ophthalmic and twice as much renal complication discharges compared with men, when diabetes lasted longer.

In both sexes, the share of renal complications showed a considerable increase, replacing ophthalmic ones as the second biggest group with the increased duration. The share of yearly bed-days of ophthalmic complications dropped in women but rose in men. Women used clearly more bed-days for ophthalmic causes than men when diabetes had lasted on average 9.5 years, but the difference leveled off when diabetes lasted longer. The most striking sex differences considering the absolute number of yearly bed-days per 1,000 patients were that women had twice as many ophthalmic and $60 \%$ more renal complication discharges when diabetes had lasted 9.5 years, and around 50\% more ophthalmic and renal complication bed-days compared to men when diabetes had lasted longer.

In terms of bed-days and discharges, men had a higher proportion in the complication group "other" than women also as the duration increased. This suggests that men were more prone to be given diagnoses "other defined" or "nondefined" complications and exact diagnoses were for some reason more seldom for men than for women.

There were vast increases in the yearly numbers of bed-days due to certain complications as the duration increased. These stress the importance of good metabolic control and management.

Hospitalizations due to endocrine complications was practically nonexistent. The small numbers of cerebrovascular bed-days was surprising. These complications possibly evolve later, and should be examined in longer periods of durations of T1DM, than this study gave possibilities (although the follow-up period was 26 years).

The number of bed-days due to neurological complications increased in women, but decreased in men, as the duration of diabetes increased. That is partly explained by the fact that the number of female users increased 3-fold while the number of male users increased by $40 \%$.

The occurrence of infectious complications might seem low. We studied hospitalizations, and many patients with infectious complications are treated as outpatients. This is the main reason for the low occurrence of infectious complications.

Also, infectious complications were spread among certain complication groups: renal complications (renal infections), peripheral vascular complications (microangiopathy, chronic ulcers etc.), and other complications. We did not want to present infections as an own group (as the grouping was mainly based on the criteria by American Diabetes Association).

The study has some limitations. No nondiabetic control group was used. Using a control group could have allowed the incremental effect of diabetes on hospitalizations to be shown. Due to difficulties in obtaining a valid and reliable control group, and due to limited resources and the scope of the study, the use of a control group was omitted. The primary diagnosis of hospital use was used to avoid double counting. This may have caused an underestimation of hospitalizations, as diabetes is often a contributory cause and is marked as a secondary diagnosis in hospital records, and they are not systematically recorded. This study was population-based, as the study population consisted of all Finnish patients with T1DM diagnosed before the age of 18 years (between 1965-1979). The study type was designed to be descriptive, not predictive or explanatory, and the main objective was to describe how hospital use changed during a long follow-up period. The data were formed by linking registers. The register data included only few variables about the population, and the possibilities to perform multivariate analyses to control possible confounding variables were small. This is why statistical modeling was not used.

For decision makers, especially in health care, it is important to know how diseases, eg, diabetes and its complications evolve as the duration increases in a long run, to help allocating resources in planning health care. We believe that this study gives more information, eg, for 
that purpose, as studies similar to this are extremely rare, practically nonexistent, especially by sex.

\section{Conclusions}

As the duration of T1DM increased from 9.5 to 16.5 years on average, the yearly numbers of bed-days due to all complications of diabetes almost tripled, while the yearly numbers of bed-days due to diabetes without complications dropped considerably. The numbers of bed-days due to renal complications, peripheral vascular diseases, and ophthalmic complications increased markedly. Women consumed clearly more bed-days than men, especially due to renal and ophthalmic complications. By preventing and delaying complications, some resources devoted to treating persons with diabetes might be allocated to treatment of other diseases, or other purposes. Additionally, extra life-years and quality of life gains should be achieved.

\section{Acknowledgments}

The authors thank Valma Harjutsalo and especially project secretary Selena Nitecki for their valuable contribution.

\section{Disclosure}

The study (part of academic $\mathrm{PhD}$ dissertation by corresponding author), later edited numerous times, was supported financially by the following organizations and foundations: Yrjö Jahnsson Foundation, Jenny and Antti Wihuri Foundation, Onni ja Hilja Tuovinen Foundation, Unit of Family Medicine at the Turku University Central Hospital, Academy of Finland, Diabetes Prevention Unit of National Institute for Health and Welfare (formerly known as Diabetes Unit of National Public Health Institute), Department of Public Health at the University of Helsinki, National School of Social and Health Administration and Economics at the University of Kuopio, Oskar Öflund Foundation, Finnish Diabetes Association.

The authors declare that they have no conflict of interest. All authors meet the criteria for authorship stated in the Uniform Requirements for Manuscripts Submitted to by Medical Journal. The manuscript includes some results that have been reported in an academic $\mathrm{PhD}$ dissertation of the corresponding author (monograph, 219 pages) in Finland and web at the University of Helsinki in October 2007. The monograph was published in the series of National Public Health Institute which has approved the publication of the results. The present manuscript has been edited several times by authors after the dissertation. The basic results have not been changed.

\section{References}

1. Leese B. The cost of diabetes and its complications. Soc Sci Med. 1992;35:1303-1310.

2. Currie CJ, Williams DR, Peters JR. Patterns of in and outpatient activity for diabetes. A district survey. Diabet Med. 1996;13:273-280.

3. Rewers A, Chase HP, Mackenzie T, et al. Predictors of acute complications in children with type 1 diabetes. JAMA. 2002;287:2511-2518.

4. Orzeck EA, Nianwen S, Blumentals WA. Oseltamivir and the risk of influenza-related complications and hospitalizations in patients with diabetes. Clin Ther. 2007;29:2246-2255.

5. Jönsson B. Diabetes - the cost of illness and the cost of control. Acta Med Scand. 1983;671(Suppl.1):19-27.

6. American Diabetes Association. Direct and indirect costs of diabetes in the United States in 1992. Alexandria, VA: American Diabetes Association; 1993.

7. Kangas T, Aro S, Koivisto VA, Salinto M, Laakso M, Reunanen A. Structure and costs of health care of diabetic patients in Finland. Diabetes Care. 1996;19:494-497.

8. American Diabetes Association. Economic consequences of diabetes mellitus in the USA in 1997. Diabetes Care. 1998;21:296-309.

9. American Diabetes Association. Economic costs of diabetes in the US in 2007. Diabetes Care. 2008;3:1-20.

10. Tomlin AM, Dovey SM, Tilyard MW. Risk factors for hospitalization due to diabetes complications. Diabetes Res Clin Pract. 2008; $80: 244-252$

11. Moss SE, Klein R, Klein BE. Risk factors for hospitalisation in people with diabetes. Arch Intern Med. 1999;159:2053-2057.

12. Fishbein H. Precipitants of hospitalisation in insulin-dependent diabetes mellitus (IDDM): A statewide perspective. Diabetes Care. 1982;8(Supp11):61-64.

13. Skyler JS; Type 1 Diabetes TrialNet Study Group. Update on worldwide efforts to prevent type 1 diabetes. Ann N Y Acad Sci. 2008;1150:190-196.

14. Knip M. Tyypin 1 diabeteksen ehkäisy. Tutkimukset kasvattavat toiveita. Diabetes ja lääkäri. 2007;36:7-12.

15. Brixner DI, McAdam-Marx C. Cost-effectiveness of insulin analogs. Am J Manag Care. 2008;14:766-775.

16. Karvonen M, Tuomilehto J, Libman I, LaPorte R. A review of the recent epidemiological data on the worldwide incidence of type 1 (insulindependent) diabetes mellitus: World Health Organization DIAMOND Project Group. Diabetologia. 1993;36:883-892.

17. Karvonen M, Pitkäniemi J, Tuomilehto J. The onset age of type 1 diabetes in Finnish children has become younger. Diabetes Care. 1999;22:1066-1070.

18. Harjutsalo V, Sjöberg L, Tuomilehto J. Time trends in the incidence of type 1 diabetes in Finnish children: a cohort study. Lancet. 2008;371:1777-1782.

19. Tuomilehto J, Rewers M, Reunanen A, et al. Increasing trend in Type 1 (insulin dependent) diabetes mellitus in childhood in Finland. Analysis of age, calendar time and birth cohort effects during 1965-1984. Diabetologia. 1991;34:282-287.

20. Major cross-country differences in risk of dying for people with IDDM. Diabetes Epidemiology Research International Mortality Study Group. Diabetes Care. 1991;14:49-54.

21. International evaluation of cause-specific mortality and IDDM. Diabetes Epidemiology Research International Mortality Study Group. Diabetes Care. 1991;14:55-60.

22. Asao K, Sarti C, Forsen T, et al. Long-term mortality in nationwide cohorts of childhood-onset T1DM in Japan and Finland. Diabetes Care. 2003;26:2038-2042.

23. Akkanen MJJ. Inpatient hospital care and its costs among type 1 diabetic patients in Finland - a nationwide longitudinal study. Dissertation, A11/ 2007. Helsinki, Finland: Publications of the National Public Health Institute; 2007.

24. American Diabetes Association. Economic consequences of diabetes mellitus in the USA in 1997. Diabetes Care. 1998;21:296-309. 
25. Lounamaa R. Mortality in Finnish patients with insulin-dependent diabetes mellitus. A follow-up study of patients diagnosed when under twenty years of age. Dissertation, ML:126. Helsinki, Finland: Publications of Social Insurance Institution; 1993.

26. Keskimäki I, Salinto M, Koskinen S. Viranomaisrekisterit terveyden ja terveyspalvelujen käytön tutkimusaineistona. Suomen Lääkäril. 1997;52:585-591

27. Keskimäki I, Aro S. Accuracy of data on diagnoses, procedures and accidents in the Finnish Hospital Discharge Register. Int J Health Sci. 1991;2:15-21.

28. Mähönen M, Salomaa V, Brommels M, et al. The validity of hospital discharge register data on coronary heart disease in Finland. Eur $J$ Epidemiol. 1997;13:403-415.

29. Nikiforov O. Yleissairaanhoito Suomessa 1960-ja 1970-luvulla. Helsinki, Finland: Lääkintöhallituksen tutkimuksia. 1984;32.
30. Salmela R, Koistinen V. Yleissairaaloiden poistoilmoitusrekistereiden kattavuus ja luotettavuus. Sairaala. 1987;49:480-482.

31. Niemi M, Winell K. Diabetes Suomessa. Esiintyvyys ja hoidon laadun vaihtelu. Helsinki, Finland: Stakes: Raportteja 8/2005;2005.

32. Kokko S. Tauti ja sairaus - työikäiset terveyskeskuslääkärin vastaanotolla. Kuopio, Finland: Kansanterveystieteen ja yleislääketieteen laitos: Kuopion yliopisto; 1988.

33. Hujanen T, Mikkola H, Pekurinen M, Häkkinen U, Teitto E. Terveydenhuollon menot ikä-ja sukupuoliryhmittäin vuonna 2002. Helsinki, Finland: Stakes: Aiheita 24/2004;2004.

34. Kivelä S-L. Miehen asennoituminen sairauteen: Mies ja terveys. Leiraksen julkaisuja. 1990;47:19-25.

\section{Publish your work in this journal}

Risk Management and Healthcare Policy is an international, peerreviewed, open access journal focusing on all aspects of public health, policy, and preventative measures to promote good health and improve morbidity and mortality in the population. The journal welcomes submitted papers covering original research, basic science, clinical \& epidemio- logical studies, reviews and evaluations, guidelines, expert opinion and commentary, case reports and extended reports. The manuscript management system is completely online and includes a very quick and fair peerreview system, which is all easy to use. Visit http://www.dovepress.com/ testimonials.php to read real quotes from published authors. 